\title{
Health fitness plan for women
}

\author{
Dr. Atmaram V. Thoke \\ Director of Physical Education, S.V.K.T. Arts, Science and Commerce College, India \\ Department of Physical Education Deolali Camp, Nashik 422401 (Maharashtra Sate)
}

\section{Introduction:}

Sports play an important role in everyone's life span It simply good for the mind, body, and soul. No one can refuse this fact. Undoubtedly sports provide us good health and fitness which is necessary for each and every human being. As sports go along way in keeping a person healthy and happy.

Sports play an important role in women's life. Actually sports in shaping all other qualities of women in her life, which make them successful among others. Women are now competing with men in every field.

Women are channelizing their power in the field of sports. Sports not only give them physical fitness but also give them status in the society and above all it gives them a feeling of satisfaction.

\section{Key of works:}

Sports keep Women fit and make them self-dependent, confident, mentally and physically strong. Women are gaining interest in sports and heading towards it to take it up as a career.

\section{Aim \& Objectives of the study:}

- To provide women opportunities to take part in physical exercise and sports in order to promote good public health,

- To support a free and independent sports movement, based on voluntary effort,

- To give women positive experiences of sports as entertainment.

- To participate in physical exercise and sports as well as their opportunities to have an influence and take responsibility for their sporting activities,

- To make it possible for women to engage in sports and physical exercise,

- To promote integration and good ethics and

- To help to arise a lifelong interest in physical exercise, thereby promoting good health for every Woman

\section{Methods \& Material:}

To find out the new methodology in Women sports for the development of human being, to remove the fear of Women sports, to update the knowledge $\&$ avoid the threats. To give scope to the inherent qualities $\&$ to increase the status of Women sports. To increase the curiosity \& interest among the Women. Competitive preparation, physical fitness, happy human life. Self study physical fitness. Make Women aware of education sports \& increase in the quality. Increase in scientific knowledge.

Majority of the Women would like to exercise but do not know how to go about it- what to do, how to do it, how often. Most of the exercise programmers call for the use of equipment and gymnasiums which are not always available. Most exercise programmers call for a great expenditure of time, which most Women cannot spare. Due to that, this resolves these problems as required.

\section{Material Observation, Analysis \& Discussion:}

These exercise programmers varies form different age groups.

\section{AS SHOWN IN THE TABLE:}

\begin{tabular}{|c|c|c|c|c|c|c|}
\hline \multirow[t]{2}{*}{ Sr. No. } & \multirow[t]{2}{*}{ Exercise } & \multicolumn{4}{|c|}{ Level of age } & \multirow{2}{*}{$\begin{array}{l}\text { Minutes for } \\
\text { each exercise }\end{array}$} \\
\hline & & 19 & 20 & 21 & 22 & \\
\hline 1 & Toe touching & 08 & 08 & 08 & 10 & \multirow{4}{*}{02} \\
\hline 2 & Knee raising & 08 & 08 & 08 & 10 & \\
\hline 3 & Lateral bending & 05 & 05 & 05 & $\mathbf{0 7}$ & \\
\hline 4 & Arm circling & 16 & 16 & 16 & 18 & \\
\hline 5 & Rocking sit ups & 07 & 09 & 12 & 14 & $\mathbf{0 2}$ \\
\hline 6 & Chest \& leg raising & 10 & 13 & 16 & 19 & 01 \\
\hline 7 & Side leg raising & 26 & 28 & 30 & 32 & 01 \\
\hline 8 & Knee push ups & 06 & 08 & 10 & 12 & 02 \\
\hline 9 & Leg over & 06 & 06 & 08 & 08 & 01 \\
\hline 10 & Run \& stride jump & 115 & 115 & 125 & 125 & 03 \\
\hline
\end{tabular}




\section{Conclusion and Discussion:}

It has been suggested Extensive research taken into the problems of physical fitness for Women, the research having been conducted at S.V.K.T. college Deolali camp in the Dist-Nashik (M.S) about 100 Women of 19 years 22 years.

The first step in the project was administration of series of physical fitness tests. The tests included an examination of muscular strength and of fat level. From the result of these tests the physical fitness needs of Women were analyzed. Finally it leads effective to general fitness. These exercise programmers varied from different age group.

Moderate and consistent levels of physical activity and sport for women are essential to good health and well-being.

Connections between physical activity and academic achievement show there is a positive relationship between the two in women.

In physical activity, less access to sport and physical fitness programs, and suffer negative health consequences as a result.

\section{References}

[1]. An introduction to Physical Education- Nixon \& Cozons Foundation of Physical Education-Bucher.

[2]. Physical Culture \& Sports in the GDR

\section{Websites:}

[3]. www. Fitness Wellness-guide.com

[4]. www.Humankinetics.com the Physical Fitness and Wellness 